ORIGINAL ARTICLE

\title{
Mortality patterns among residents in Lovisiana's industrial corridor, USA, 1970-99
}

\author{
S P Tsai, K M Cardarelli, J K Wendt, A E Fraser
}

Occup Environ Med 2004;61:295-304. doi: 10.1136/oem.2003.007831

See end of article for authors' affiliations ......................

Correspondence to: Dr S P Tsai, Shell Oil Company, Shell Health Services-USA, One Shell Plaza, PO Box 2463 Houston, Texas 77252 2463, USA;

shan.tsai@shell.com

Accepted 7 May 2003
Background: Because of the high concentration of oil refining and petrochemical facilities, the industrial area of the lower Mississippi River of South Lovisiana has been termed the Industrial Corridor and has frequently been referred to as the "Cancer Corridor".

Aims: To quantitatively assess the "Cancer Corridor" controversy based on mortality data available in the public domain, and to identify potential contributing factors to the observed differences in mortality.

Methods: Age adjusted mortality rates were calculated for white and non-white males and females in the Industrial Corridor, Lovisiana, and the United States for the time periods 1970-79, 1980-89, and 1990-99.

Results: All-cause mortality and all cancer combined for white males in the Industrial Corridor were significantly lower than the corresponding Lovisiana population while Lovisiana had significantly higher rates than the US population for all three time periods. Cancer of the lung was consistently higher in the Industrial Corridor region relative to national rates but lower than or similar to Louisiana. Non-respiratory disease and cerebrovascular disease mortality for white males in the Industrial Corridor were consistently lower than either Louisiana or the USA. However, mortality due to diabetes and heart disease, particularly during the 1990s, was significantly higher in the Industrial Corridor and Lovisiana when compared to the USA. Similar mortality patterns were observed for white females. The mortality for non-white males and females in the Industrial Corridor was generally similar to the corresponding populations in Louisiana. There were no consistent patterns for all cancer mortality combined. Stomach cancer was increased among non-whites in both the Industrial Corridor and Louisiana when compared to the corresponding US data. Mortality from diabetes and heart disease among non-whites was significantly higher in the Industrial Corridor and Louisiana than in the USA.

Conclusions: Mortality rates in the Industrial Corridor area were generally similar to or lower than the State of Louisiana, which were increased compared to the United States. Contrary to prior public perceptions, mortality due to cancer in the Industrial Corridor does not exceed that for the State of Lovisiana.
O ver the past 20 years, Louisiana has been the focus of public and governmental concerns relating to human health effects possibly associated with occupational hazards and environmental pollution. Louisiana is the second largest producer of industrial and agricultural organic chemicals and third largest producer of plastics, synthetics, and industrial inorganic chemicals in the United States. ${ }^{1}$ Chemicals that have been released by these industries include ammonia, methanol, phosphoric acid, nitrate compounds, formaldehyde, and polycyclic aromatic hydrocarbons. ${ }^{2}$

Because of a high concentration of refinery and petrochemical facilities, the industrial area of South Louisiana near the lower Mississippi River, has been termed the Industrial Corridor, "Chemical Corridor", or "Cancer Corridor". ${ }^{3}$ The petrochemical industry in this area has been cited as a major pollution source, prompting concerns about the potential adverse impact on health among employees and nearby residents. The Industrial Corridor includes seven parishes: Ascension, East Baton Rouge, Iberville, St Charles, St James, St John the Baptist, and West Baton Rouge. $^{3-5}$

Many studies of cancer incidence and mortality in Industrial Corridor residents and petrochemical employees have been conducted. ${ }^{3-13}$ These studies generally have not shown significantly increased mortality or incidence for most types of cancer, with the exception of lung and pancreas cancer in white males. ${ }^{4}{ }^{12}{ }^{13}$ Recently, an increase in prostate cancer incidence was reported among Industrial Corridor white males, but not among black males. ${ }^{514}$ Studies examining the relation between residential proximity to industry and lung cancer are not consistent in Louisiana. Based on death certificates only, one study concluded that persons residing close to industry experienced higher lung cancer mortality. ${ }^{16}$ However, a subsequent study using survey data suggested that residential proximity to industrial sites in Louisiana was not associated with increased lung cancer. ${ }^{17}$ There are no other published reports on mortality patterns for the Industrial Corridor population.

The objectives of the present study were to compare mortality rates for major causes of death in the Industrial Corridor, Louisiana, and the USA and to identify potential contributing social, economic, and behavioural factors to mortality.

\section{METHODS}

The age, sex, race (white and non-white), and cause specific numbers of deaths and corresponding populations for the Industrial Corridor, Louisiana, and USA were obtained from the University of Pittsburgh's Mortality and Population Data System (MPDS). ${ }^{18}$ Causes of death were classified according to the International Classification of Diseases, ninth revision. The leading causes of death in the USA were chosen for study as well as certain cancer causes based on prior literature. ${ }^{19}$ ICD codes examined in this study are listed in the appendix. 


\section{Main messages}

- This study found that overall mortality and cancer mortality rates for the Industrial Corridor are, in general, lower than or similar to those of Lovisiana, which are increased compared to the United States.

- The raised lung cancer mortality rates among white males in Lovisiana have been seen for several decades, but lung cancer in the Industrial Corridor was consistently lower than the state average. Therefore, it is likely that the Industrial Corridor did not contribute to the excess mortality of lung cancer in Louisiana.

- Mortality for pancreatic cancer was general higher in the Industrial Corridor and Lovisiana compared to the USA.

- Mortality due to diabetes and heart disease were significantly higher in the Industrial Corridor and Lovisiana compared to the USA, especially for nonwhite females.

- Non-malignant respiratory disease mortality was no different for non-white males and females in the Industrial Corridor compared to Louisiana, but was significantly lower for white males and females in the Industrial Corridor.

Age adjusted mortality for the four race-sex groups were calculated for the Industrial Corridor, Louisiana, and USA using the 2000 US Standard Million Population. Ninety five per cent confidence intervals were calculated, based on an approximate standard error proposed by Keyfitz. ${ }^{20}$ To minimise random fluctuations, rates were expressed as average annual rates per 100000 for the time periods 1970-79, 198089, and 1990-99. An age adjusted rate for a specific cause in the Industrial Corridor (or Louisiana) was significantly different from the US rate if the $95 \%$ confidence interval of the adjusted rate of the Industrial Corridor (or Louisiana) did not include the US point estimate. A two-sample statistical method was used to compare rates between the Industrial Corridor and Louisiana. ${ }^{21}$

Childhood mortality for all causes, all cancers combined, and leukaemia was calculated for children younger than 15 years of age. Childhood mortality was adjusted to the 2000 US Standard Million Population for three age groups: 0-4, 5-9, and 10-14. Because of the small number of childhood deaths, cancer mortality was calculated by race-sex subgroups, but not calendar time.

Industrial Corridor "non-white" data are comparable to Louisiana, but not to the USA, because blacks contribute a substantially higher proportion to the "non-white" population in Louisiana than in the USA (for 1990, 96\% in the Industrial Corridor and $94 \%$ in Louisiana versus $61 \%$ in the USA). ${ }^{22}$ Therefore, US data for black males and females for $1975,{ }^{23} 1985,{ }^{24}$ and $1995^{25}$ were compared to non-whites in the Industrial Corridor and Louisiana for the three time periods. Due to a lack of comparable data for US black males and females for 1975 and 1985, kidney and bladder cancer cases (as defined for this study) were combined for the first two time periods. Hispanic ethnicity was not examined because it comprised only $2 \%$ of the Louisiana population in 1990 compared to $9 \%$ in the USA. ${ }^{26}$

Life expectancy at birth for the Industrial Corridor and Louisiana was calculated using Chiang's method. ${ }^{27}$ Average population and deaths for the three time periods were used in this analysis.

\section{Policy implications}

- Compared to the USA, Lovisiana has greater unemployment and poverty, and lower educational attainment and per capita income. The higher overall mortality rate in Louisiana is consistent with the demonstrated gradient that mortality follows across socioeconomic status. In contrast, fewer persons in the Industrial Corridor are impoverished or are unemployed compared to Lovisiana.

- Rates of obesity, smoking, sedentary lifestyle, and alcohol consumption, and lack of access to a primary care provider and health insurance in Lovisiana exceed national averages. These health risk factors could have contributed to the higher levels of heart disease, lung cancer, pancreatic cancer, and diabetes in this state.

- Social factors peripheral to health care access or utilisation may have a major impact on the mortality of populations in Louisiana.

\section{RESULTS}

\section{Mortality patterns}

White males

All-cause and all-cancer mortality for Industrial Corridor white males (table 1) was significantly lower than the corresponding Louisiana population, while Louisiana had significantly higher all-cause and all-cancer mortality than US white males for all three time periods. Consistently, lung cancer was significantly higher in the Industrial Corridor relative to national rates, but lower than or similar to Louisiana. Similar patterns were observed for pancreas cancer. White males in the Industrial Corridor had consistently lower mortality from prostate cancer, non-malignant respiratory disease, and cerebrovascular disease than Louisiana and the USA. However, white males in the Industrial Corridor and Louisiana had significantly higher heart disease mortality than in the USA during the study periods. Mortality due to kidney, bladder, stomach, and central nervous system cancers and leukaemia in the Industrial Corridor generally was not significantly different from the USA. Although similar to Louisiana, liver and biliary tract cancer mortality was increased in the Industrial Corridor in the 1980s and 1990s, compared to the USA. Diabetes mortality in the Industrial Corridor was similar to the USA during the 1970s and 1980s but significantly higher in the 1990s.

\section{White females}

The pattern of all-cause mortality for white females (table 2) was similar to that seen in white males-that is, significantly lower in the Industrial Corridor compared to Louisiana and significantly higher in Louisiana than in the USA. Mortality for all neoplasms combined in the Industrial Corridor and Louisiana was significantly lower than in the USA during the 1970s, but was significantly higher in Louisiana than in the USA during the 1990s. Mortality for cancers of the kidney, bladder, liver and biliary tract, and stomach, and leukaemia was similar between the USA and Industrial Corridor. Lung and central nervous system cancer mortality in the Industrial Corridor were generally the same as Louisiana but higher than the USA in the 1990s. Pancreas cancer was consistently higher in the Industrial Corridor and Louisiana. Like their male counterparts, cerebrovascular disease mortality was 


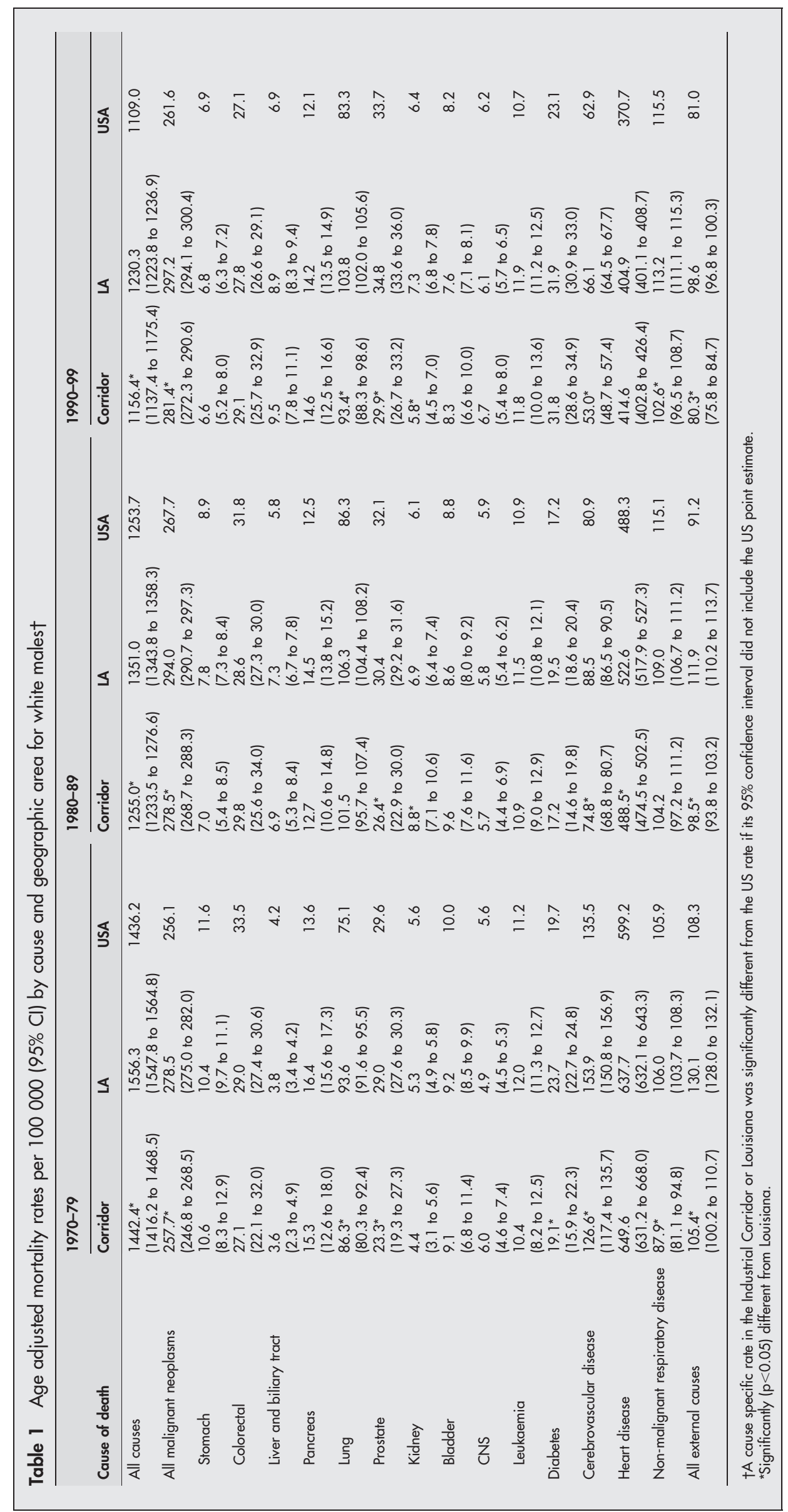


离

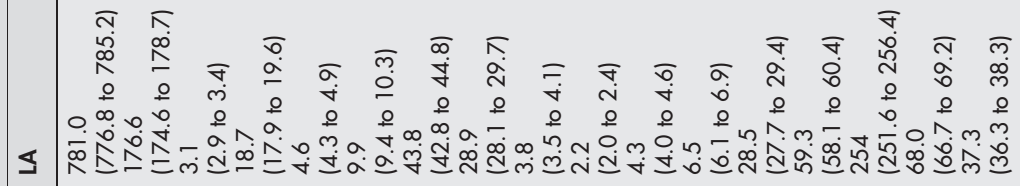

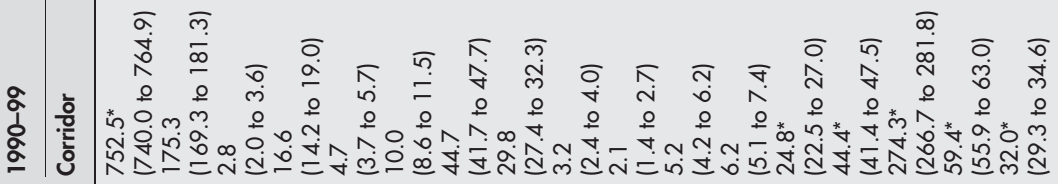

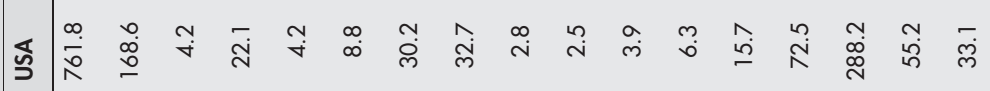

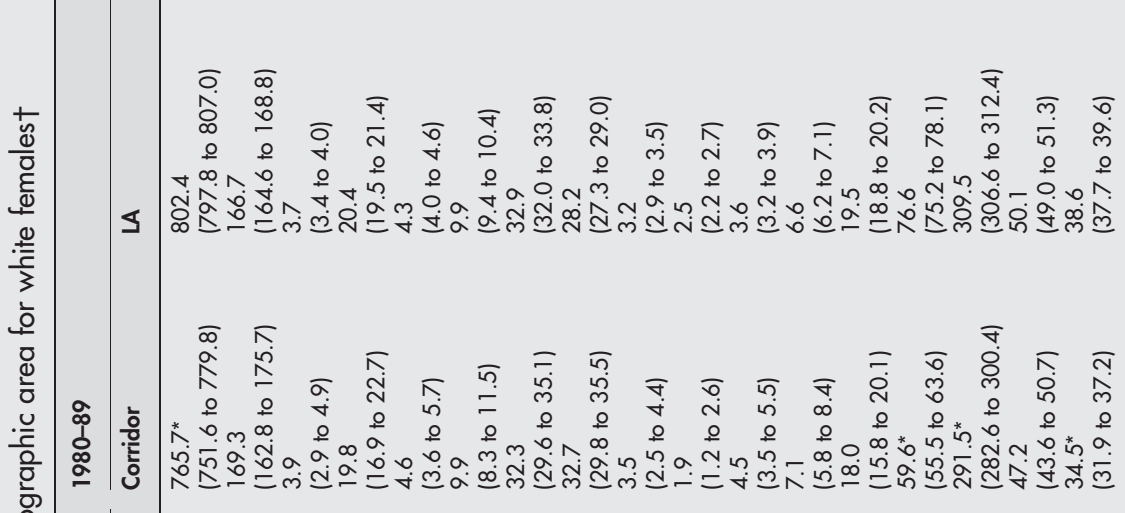

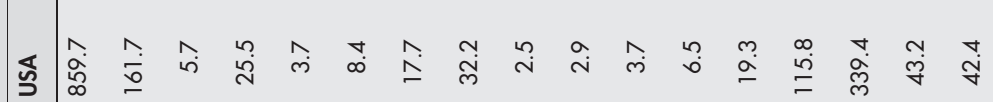

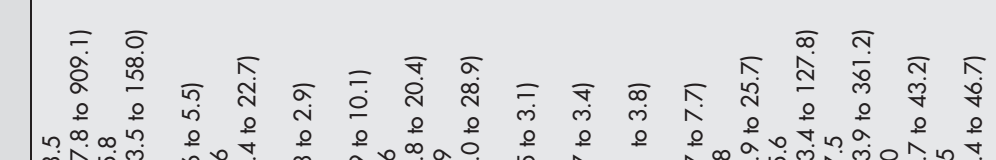

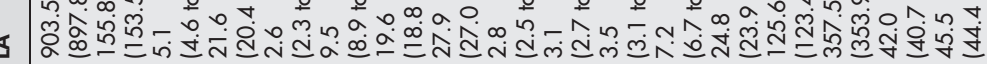

\section{$\bar{a}$}

$=$

रิ

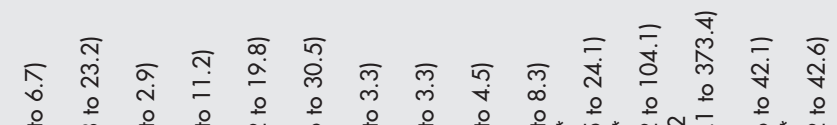

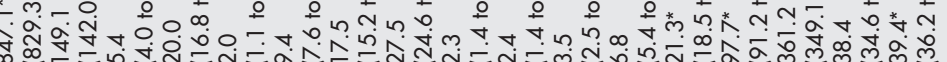


significantly lower in the Industrial Corridor than Louisiana or the USA, as was mortality from non-malignant respiratory disease. Compared to the USA, heart disease and diabetes mortality were significantly increased in both the Industrial Corridor and Louisiana.

\section{Non-white males}

Mortality for non-white males in the Industrial Corridor was generally similar to the corresponding population in Louisiana (table 3). In general, there were no statistical differences for all causes of death, all cancers or any specific cancer, or non-malignant respiratory disease between the Industrial Corridor and Louisiana. However, overall mortality for the Industrial Corridor and Louisiana was higher than the comparable US population. Diabetes and heart disease mortality were significantly higher in both the Industrial Corridor and Louisiana compared to the USA during the entire study period. Mortality for cancers of the bladder, kidney, and central nervous system, and leukaemia in the Industrial Corridor was about the same as Louisiana and the USA. Compared to the USA, liver and biliary tract cancer mortality in the Industrial Corridor was slightly higher in the 1980s and 1990s after being lower in the 1970s. Mortality from all cancers combined, pancreas cancer, and lung cancer in the 1990s was higher in both the Industrial Corridor and Louisiana than in the USA although rates in the Industrial Corridor were lower than those of Louisiana. Stomach cancer mortality was consistently higher in the Industrial Corridor and Louisiana, but prostate cancer was significantly lower when compared to the USA.

\section{Non-white females}

All-cause mortality among Industrial Corridor non-white females was similar to Louisiana, but significantly higher than the USA (table 4). There were no statistical differences in mortality for all cancers combined between the three populations for the three time periods. Like their male counterparts, stomach cancer was higher in all three time periods in the Industrial Corridor and Louisiana. In the 1970s, pancreas cancer was significantly lower in the Industrial Corridor and Louisiana compared to the USA, but significantly higher in the 1990s. Cancer of the central nervous system was marginally increased compared to both Louisiana and the USA during the 1990s. There were no statistically significant differences for any other specific cancer sites, although mortality from cancers of the kidney and bladder in the Industrial Corridor was consistently lower than the USA for the entire study period. Cerebrovascular disease mortality during the 1990s was significantly lower in the Industrial Corridor compared to Louisiana or the USA. However, heart disease mortality was significantly higher among Industrial Corridor residents compared to those in Louisiana or the USA for all three time periods. Diabetes mortality was significantly higher in the Corridor than in the USA, and surpassed stroke to become the third leading cause of death in this population in the 1990s.

\section{Childhood mortality}

Table 5 shows age adjusted mortality for children under the age of 15 in the Industrial Corridor, Louisiana, and the USA. For both white males and females, total mortality from all causes was significantly lower in the Industrial Corridor than Louisiana or the USA. Among non-white children, the overall mortality for males in the Industrial Corridor was significantly lower than Louisiana or the USA, but was similar for females. There were no statistically significant differences for cancer or leukaemia deaths among whites or non-whites between the Industrial Corridor and Louisiana or the USA.

\section{Life expectancy}

Life expectancy at birth for the Industrial Corridor, Louisiana, and the USA are presented in table 6. Life expectancy at birth among whites in the Industrial Corridor was similar to that of the USA but better than Louisiana. Life expectancies for white males in the 1990s, compared to the 1970s, increased 4.4 years for the Industrial Corridor, 4.2 years for Louisiana, and 4.3 years for the USA. Similar patterns were noted for white females.

Life expectancy at birth for non-whites in the three geographic areas was similar for all three time periods. When compared to 1970-79, life expectancy at birth for the Industrial Corridor, Louisiana, and the USA during 1990-99 increased 2.7, 3.0, and 2.8 years, respectively, for non-white males and 3.2, 3.5, and 2.6 years for non-white females.

\section{DISCUSSION}

Age adjusted mortality in the Industrial Corridor for all three time periods and race-sex groups generally followed the same racial and gender patterns as in Louisiana and the USA. Nonwhite males consistently exhibited the highest mortality, followed by white males, non-white females, and white females. In addition, all-cause mortality declined over the 30 year study period and cancer mortality steadily increased in all three populations. Diabetes mortality decreased slightly from the 1970s to the 1980s but sharply increased in the 1990s, especially in non-whites. Mortality for heart disease and cerebrovascular disease consistently decreased during the study period. Lung cancer and non-malignant respiratory disease mortality generally increased except among white males, who experienced a decrease during the 1990s.

This study showed that mortality for the Industrial Corridor is generally similar to or lower than that of Louisiana, which is increased compared to the USA. Compared to Louisiana, there was no excess mortality risk among Industrial Corridor residents for all causes or all cancers combined regardless of gender or race. During the 30 year study period, life expectancies at birth among Industrial Corridor residents were approximately the same as the corresponding US population. However, compared to Louisiana, whites in the Industrial Corridor enjoyed a longer life expectancy (0.7 to 1.7 years), which was less evident in non-whites $(-0.2$ to 0.5 years).

Other studies have found few significant associations between residential proximity to industry and either disease incidence or mortality. ${ }^{28-31}$ One study in the San Francisco Bay area concluded that residence near petrochemical industry had no effect on cancer incidence. ${ }^{28}$ Other studies in Wales found increases in multiple myeloma, Hodgkin's disease, and non-Hodgkin's lymphoma incidence, but could not rule out chance due to multiple statistical tests. ${ }^{30} 31$

Increased lung cancer mortality among white males in Louisiana has been observed for several decades, ${ }^{32}$ and is consistent with results for lung cancer incidence. ${ }^{45}$ Currently, the highest lung cancer rates in the nation are observed across the southeast with Louisiana ranked fifth nationally. ${ }^{21}$ Since lung cancer in the Industrial Corridor was consistently lower than or similar to the state average, it is likely that the Industrial Corridor did not contribute to the excess mortality of lung cancer in Louisiana, assuming that smoking rates were similar. Available data show that smoking prevalence in Louisiana in the 1990s was higher than the national average (table 7), and one study estimated that male residents in South Louisiana prior to 1990 tended to smoke more than the rest of the nation..$^{17} \mathrm{~A}$ diet low in fruits and vegetables has also been found to increase the risk of lung cancer 50$100 \%,{ }^{36} 37$ and it is noteworthy that a survey conducted in 1968-70 reported low vitamin C intake among Louisiana residents. ${ }^{38}$ 


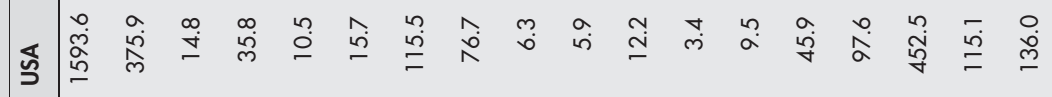

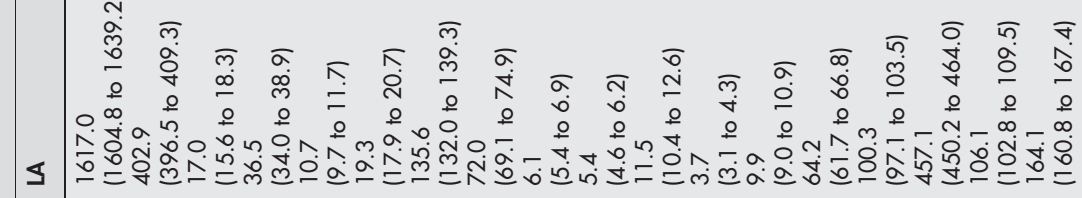

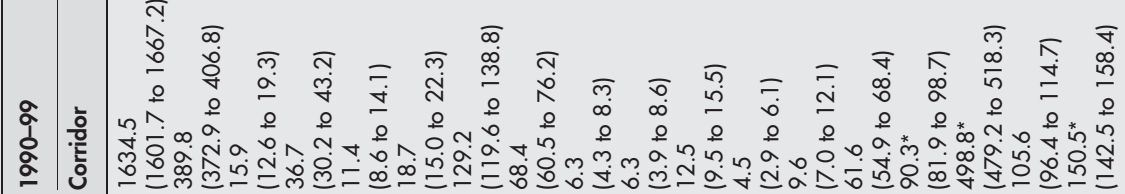
孚

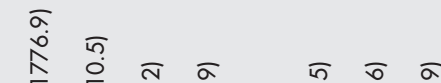

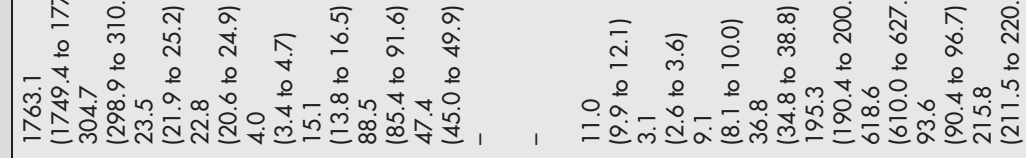




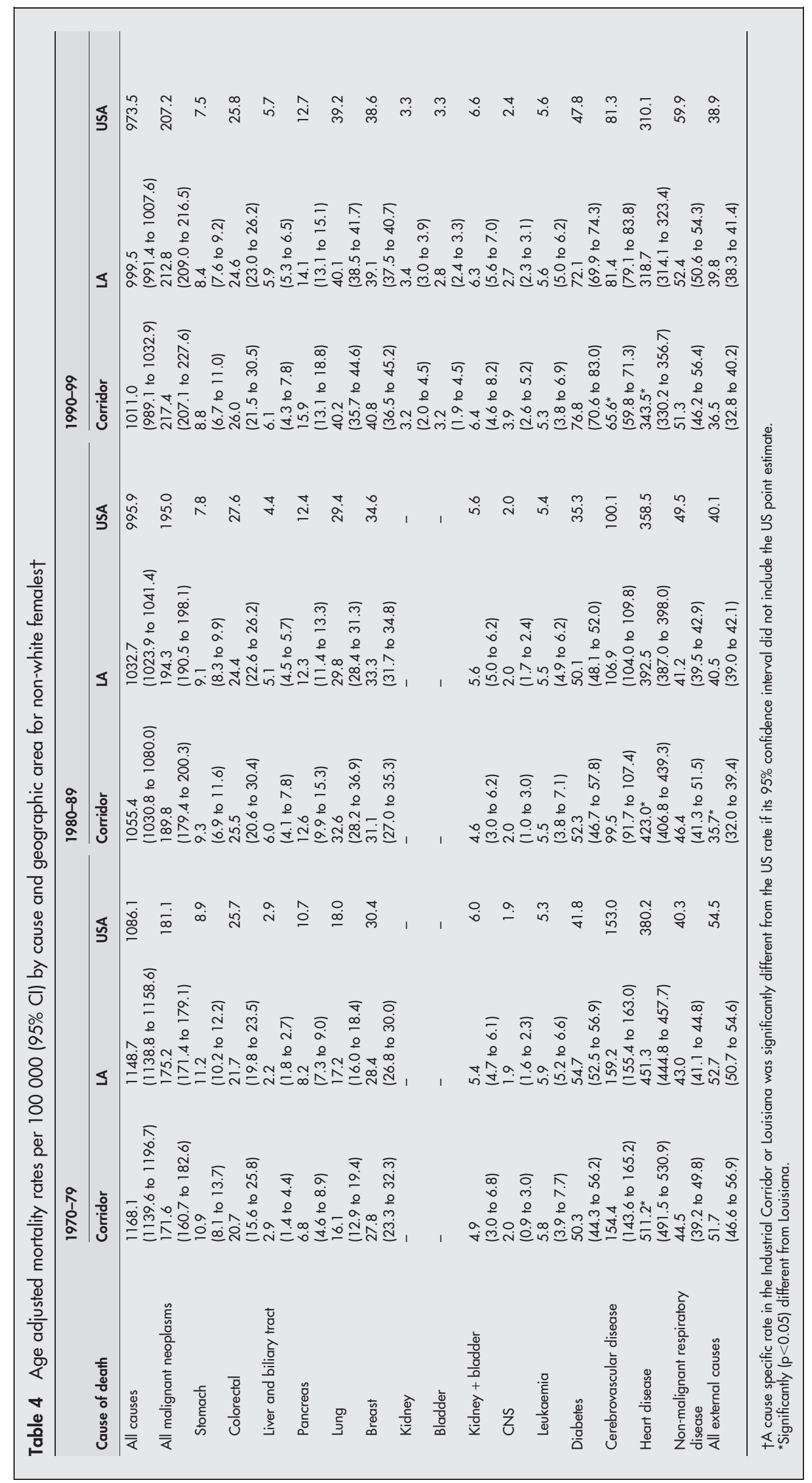


Table 5 Age adjusted childhood (ages 0-14) mortality rates per 100000 and $95 \% \mathrm{Cl}$ by race, sex, and geographic area, 1970-99

\begin{tabular}{lllll}
\hline Cause of death & White males & White females & Non-white males & Non-white females \\
\hline All causes & $97.5(92.2$ to 102.7$)$ & $74.9(70.2$ to 79.6$)$ & $191.3(182.4$ to 200.2$)$ & $165.2(156.9$ to 173.6$)$ \\
$\begin{array}{l}\text { Corridor } \\
\text { Louisiana }\end{array}$ & $118.9(116.8$ to 121.0$)$ & $88.2(86.3$ to 90.1$)$ & $209.6(206.1$ to 213.2$)$ & $165.1(161.9$ to 168.3$)$ \\
$\begin{array}{l}\text { USA } \\
\text { All cancer }\end{array}$ & $110.2(109.9$ to 110.4$)$ & $83.1(82.9$ to 83.3$)$ & $202.5(200.1$ to 205.0$)$ & $159.6(157.4$ to 161.8$)$ \\
$\quad \begin{array}{l}\text { Corridor } \\
\text { Louisiana }\end{array}$ & $3.9(2.9$ to 5.0$)$ & $2.8(1.9$ to 3.8$)$ & $4.1(2.8$ to 5.4$)$ & $3.6(2.4$ to 4.9$)$ \\
USA & $4.3(3.9$ to 4.7$)$ & $3.4(3.1$ to 3.8$)$ & $4.1(3.6$ to 4.6$)$ & $3.2(2.8$ to 3.7$)$ \\
Leukaemia & $4.5(4.5$ to 4.6$)$ & $3.5(3.5$ to 3.6$)$ & $3.7(3.4$ to 4.1$)$ & $3.5(3.2$ to 3.9$)$ \\
$\quad$ Corridor & $1.43(0.79$ to 2.08$)$ & $1.42(0.76$ to 2.08$)$ & $1.33(0.58$ to 2.08$)$ & $1.01(0.35$ to 1.67$)$ \\
Louisiana & $1.67(1.42$ to 1.92$)$ & $1.34(1.10$ to 1.57$)$ & $1.47(1.17$ to 1.77$)$ & $1.07(0.81$ to 1.32$)$ \\
USA & $1.85(1.82$ to 1.88$)$ & $1.40(1.37$ to 1.43$)$ & $1.34(1.28$ to 1.40$)$ & $1.07(1.02$ to 1.12$)$ \\
\hline
\end{tabular}

Table 6 Life expectancy at birth in years by race and geographic area

\begin{tabular}{|c|c|c|c|c|c|c|c|c|c|}
\hline & \multicolumn{3}{|l|}{$1970-79$} & \multicolumn{3}{|l|}{$1980-89$} & \multicolumn{3}{|l|}{ 1990-99 } \\
\hline & Corridor & Louisiana & USA & Corridor & Louisiana & USA & Corridor & Louisiana & USA \\
\hline $\begin{array}{l}\text { White males } \\
\text { White females } \\
\text { Non-white males } \\
\text { Non-white females }\end{array}$ & $\begin{array}{l}69.3 \\
77.6 \\
62.4 \\
70.6\end{array}$ & $\begin{array}{l}67.8 \\
76.4 \\
62.1 \\
70.5\end{array}$ & $\begin{array}{l}69.3 \\
77.1 \\
62.4^{\star} \S \\
71.3^{*}\end{array}$ & $\begin{array}{l}71.9 \\
78.9 \\
65.4 \\
73.0\end{array}$ & $\begin{array}{l}70.5 \\
78.2 \\
64.9 \\
73.2\end{array}$ & $\begin{array}{l}71.7 \\
78.9 \\
65.0+\S \\
73.4+9\end{array}$ & $\begin{array}{l}73.7 \\
79.5 \\
65.1 \\
73.8\end{array}$ & $\begin{array}{l}72.0 \\
78.8 \\
65.1 \\
74.0\end{array}$ & $\begin{array}{l}73.6 \\
79.8 \\
65.2 \ddagger \S \\
73.9 \pm\end{array}$ \\
\hline \multicolumn{10}{|c|}{$\begin{array}{l}\text { *Data point from } 1975 . \\
\text { †Data point from } 1985 \\
\text { †Data point from } 1995 . \\
\text { §Life expectancy for US black males. } \\
\text { - Life expectancy for US black females. }\end{array}$} \\
\hline
\end{tabular}

Studies of workers in the shipping, sugarcane, and asbestos related industries in Louisiana have shown increases in lung cancer, while refinery and petrochemical workers had no excess for all cancer combined or lung cancer. ${ }^{11}$ However, a recent review of mortality and cancer incidence among chemical workers in the USA and Western Europe reported a weak to moderate excess of lung cancer likely caused by occupational exposure to known lung cancer carcinogens. ${ }^{39}$ Since the Industrial Corridor parishes are located in the nation's highest density of petrochemical facilities, the US government has funded several in-depth studies which will evaluate the impact of industrial chemical exposure on lung cancer aetiology, focusing on gene-environment interactions. ${ }^{40}$

Increased pancreatic cancer mortality in the Industrial Corridor was observed in non-whites, particularly in females, and has been previously reported in Louisiana. ${ }^{45}$ The only well established risk factors for pancreatic cancer are cigarette smoking ${ }^{41}$ and occupational exposure to chlorinated hydrocarbons. ${ }^{42}$ Several population based case-control studies in Louisiana found that a history of smoking was associated with a twofold increase in pancreas cancer. ${ }^{41}{ }^{43}$ Differences in smoking prevalence might be partly responsible for the observed regional difference in pancreatic cancer. Some studies have shown a significant increase in pancreas cancer risk in those of Cajun ethnicity and among those consuming diets poor in fresh fruits, ${ }^{41}{ }^{44}$ although this result is not consistent. ${ }^{45}$ It is also noteworthy that diabetes mellitus, which has been positively associated with pancreatic cancer, ${ }^{45}$ was higher in Louisiana. However, it is unknown if these diseases are consequences of a common exposure or are causally related.

Liver and biliary tract cancer mortality was lower in the Industrial Corridor and Louisiana than the USA in the 1970s but higher in the 1980s and 1990s. Rates have risen more quickly for males than for females. Increased liver and biliary tract cancer mortality in Louisiana has not previously been reported. Liver cancer incidence data is available for Louisiana and the Industrial Corridor during 1983-87, and for Louisiana as a whole during 1993-97. In the 1980s, liver cancer incidence in Louisiana and the Industrial Corridor was virtually the same or lower than national rates for all sex-race groups. ${ }^{3}$ In the 1990s, liver cancer incidence in Louisiana was similar to the USA based on data from the North American Association of Central Cancer Registries, although the rate for white males was slightly higher than the USA while the corresponding rate for black males was slightly lower. ${ }^{5}$ Based

Table 7 Behavioural and social risk factor prevalence for the state of Louisiana, and the USA*

\begin{tabular}{lll}
\hline Risk factor & Louisiana (\%) & USA (\%) \\
\hline Obesity (1995) & 17.7 & 15.8 \\
Smoking (1995) & 25.3 & 22.4 \\
Alcohol consumption† (1995) & & \\
$\quad$ 1-2 drinks & 62.5 & 67.6 \\
$\quad 3$ drinks & 37.5 & 32.3 \\
Exercise (1996) & 65.1 & 72.3 \\
Uninsured population (1998) & 19.0 & 16.3 \\
Below 100\% poverty level (1998) & 21.6 & 13.1 \\
Without access to primary care provider & 33.4 & 17.1 \\
(1996) & $\$ 10635$ & $\$ 14387$ \\
Personal per capita income (1990) & 9.6 & 6.3 \\
Unemployed (1990) & 68.3 & 75.2 \\
High school graduate or higher (1990) & 16.1 & 20.3 \\
Bachelor's degree or higher (1990) & 16.3 \\
\hline
\end{tabular}

*Sources: Centers for Disease Control, ${ }^{33}$ Health Resources and Services Administration, ${ }^{34} 35$ US Census Bureau. ${ }^{22}$

†Average number of drinks on days when alcohol was consumed. ‡Any exercise in the past month. 


\begin{tabular}{|c|c|c|c|c|}
\hline & $\begin{array}{l}\text { Industrial Corridor } \\
1980\end{array}$ & $\begin{array}{l}\text { Louisiana } \\
1980\end{array}$ & $\begin{array}{l}\text { Industrial Corridor } \\
1990\end{array}$ & $\begin{array}{l}\text { Louisiana } \\
1990\end{array}$ \\
\hline Total population & 558182 & 4205900 & 592099 & 4314085 \\
\hline$\%$ White & 62.7 & 69.2 & 64.4 & 66.7 \\
\hline$\%$ Black & 32.4 & 29.4 & 34.1 & 31.3 \\
\hline \multicolumn{5}{|l|}{ Occupation } \\
\hline Agriculture & 1.1 & 2.2 & 1.4 & 2.5 \\
\hline Manufacturing & 18.6 & 14.4 & 18.2 & 12.5 \\
\hline Mining & 1.3 & 5.0 & 0.7 & 3.2 \\
\hline Health and hospitals & 5.4 & 7.0 & 7.2 & 9.0 \\
\hline Persons below poverty level (\%) & 16.1 & 18.6 & 19.7 & 23.6 \\
\hline Per capita income & $\$ 7045$ & $\$ 6430$ & $\$ 12163$ & $\$ 10635$ \\
\hline \multicolumn{5}{|l|}{ Persons living in rural areas } \\
\hline$\%$ White & 25.1 & 34.6 & 25.5 & 37.0 \\
\hline$\%$ Black & 22.7 & 24.2 & 18.1 & 21.7 \\
\hline \multicolumn{5}{|l|}{ Education level } \\
\hline \% High school graduate or higher & - & 57.7 & 78.1 & 68.3 \\
\hline \% Bachelor's degree or higher & - & 14.0 & 21.5 & 16.1 \\
\hline Unemployed (\%) & - & - & 8.3 & 9.6 \\
\hline $\begin{array}{l}\text { Current smokers }(\%) \text {, average } \\
1995-98^{*}\end{array}$ & - & - & $24-32$ & 26 \\
\hline
\end{tabular}

on this ecological study, it is difficult to determine the aetiology of the higher mortality for these cancers in Louisiana and the Industrial Corridor.

Although much attention has been given to potential health effects from industrial pollution, the influence of other environmental and socioeconomic factors on the health of populations is well documented. Neighbourhood safety, economic conditions, resident education level, occupational safety, access to health care, and other social and behavioural factors have been recognised as important determinants of health in a community. ${ }^{46} 47$ The three most prominent contributors to US mortality are behaviour related: tobacco, diet and activity patterns, and alcohol. ${ }^{19}$

Compared to the USA, Louisiana has greater unemployment and poverty, and lower educational attainment and per capita income (table 7). The higher overall mortality and lower life expectancy in Louisiana are consistent with the demonstrated gradient of mortality across socioeconomic status. ${ }^{47}$ Furthermore, rates of obesity, smoking, sedentary lifestyle, alcohol consumption, and lack of access to health care in Louisiana exceed national rates. These factors could have contributed to the higher levels of heart disease, lung cancer, pancreatic cancer, and diabetes in this state, ${ }^{48} 49$ although data needed to investigate this were not available.

Since 1980, per capita income and educational attainment have been consistently higher in the Industrial Corridor than the state of Louisiana (table 8). Fewer persons in the Industrial Corridor are impoverished, unemployed, or live in rural areas. This generally higher socioeconomic status is reflected in the significantly lower overall mortality for whites. However, mortality rates for non-whites living in the Industrial Corridor were no different than those for Louisiana.

One of the more striking findings of this study was the significantly increased diabetes mortality in Louisiana during the 1990s, especially among Industrial Corridor non-white females. Diabetes prevalence increased by a third in the USA during the 1990s. In Louisiana, the rate was slightly higher, $35 \% .{ }^{51}$ Heart disease mortality was also significantly higher in Louisiana, particularly for Industrial Corridor residents. Smoking prevalence estimates are similar in the Industrial Corridor and Louisiana overall (table 8), yet lung cancer mortality rates were generally lower in the Industrial Corridor than the corresponding state population. Despite the presence of air emissions from area industries, nonmalignant respiratory disease mortality was also lower for Industrial Corridor residents.

Several limitations of this study should be recognised. The inability to obtain sex and race specific prevalence data for certain potential confounding factors (for example, smoking, income, dietary habits) limits the ability to draw conclusions about the contribution of such behavioural risk factors to disease outcomes. Second, this study is ecological in design, thereby limiting the ability to draw causal relations due to the potential for the "ecologic fallacy". ${ }^{52}$ Third, for the leading causes of death and for common cancers such as lung, prostate, colon, and breast, mortality is stable because it is based on a large number of deaths. However, for rare cancers such as brain, liver and biliary tract, and kidney, the rates are less stable.

\section{Authors' affiliations}

S P Tsai, J K Wendt, A E Fraser, Shell Oil Company, Shell Health Services-USA, One Shell Plaza, PO Box 2463, Houston, Texas, USA K M Cardarelli, The University of Texas Health Science Center at Houston, School of Public Health, Houston, Texas, USA

\section{APPENDIX}

The following specific causes and ICD codes were examined in this study: all malignant neoplasms (140-209), stomach cancer (151), colorectal cancer (153-154), liver and biliary tract cancer including gallbladder and bile ducts (155-156), pancreas cancer (157), lung cancer (162), breast cancer (174), prostate cancer (185), bladder cancer (188, 189.3189.4, 189.8-189.9), kidney cancer (189.0-189.2), central nervous system cancer (191-192), leukaemia (204-208), diabetes mellitus (250), cerebrovascular disease (430-438), heart disease (390-398, 402, 404, 410-429), non-malignant respiratory disease (460-519), and all external causes of deaths (E800-E999).

\section{REFERENCES}

1 Scott LC. The chemical industry in Louisiana: economic profile. Baton Rouge, LA: Lovisiana Chemical Association, 1993.

2 US Environmental Protection Agency. Toxics Release Inventory-Louisiana, 2000. http://www.epa.gov/triinter/tridata/tri00/state/Louisiana.pdf. Accessed 14 April 2003.

3 Groves FD, Andrews PA, Chen WW, et al. Is there a 'cancer corridor' in Louisiana? J La State Med Soc 1996;148:155-65. 
4 Chen VW, Andrews PA, Wu XC, et al. Cancer incidence in the industrial corridor: an update. J La State Med Soc 1998;150:158-67.

5 Wu XC, Correa CN, Andrews PA, et al. Cancer incidence and mortality in Louisiana, 1993-1997. New Orleans, LA: Louisiana Tumor Registry, 2001.

6 Tsai SP, Gilstrap EL, Colangelo TA, et al. A mortality study of oil refinery and petrochemical employees. J Occup Environ Med 1997;39:448-54.

7 Shallenberger LG, Acquavella JF, Donaleski D. An update mortality study of workers in three major United States refineries and chemical plants. $\mathrm{Br} J$ Ind Med 1992:49:345-54.

8 Olson GW, Kusch GD, Stafford BA, et al. The mortality experience of Dow Chemical Louisiana Division employees, 1956-1986. J La Stat Med Soc 1992; 144:529-32.

9 Ott MG. Mortality experience among Louisiana chemical manufacturing employees, 1957-1992. J La State Med Soc 1996;148:260-6.

10 Huebner WW, Chen WW, Friedlander BR, et al. Incidence of lymphohaematopoietic malignancies in a petrochemical industry cohort: 1983-94 follow-up. Occup Environ Med 2000;57:605-14.

11 Wong O, Foliart D. Epidemiological factors of cancer in Louisiana. J Environ Pathol Toxicol Oncol 1993;12:171-83.

12 Gottlieb MS. Lung cancer and the petroleum industry in Louisiana. J Occup Med 1980;22:384-8

13 Pickle LW, Gottlieb MS. Pancreatic cancer mortality in Louisiana. Am J Public Health 1980:70:256-9.

14 Andrews PA, Wu XC, Correa CN, et al. Cancer incidence and mortality in Lovisiana, 1991-1995. New Orleans, LA: Louisiana Tumor Registry, 2000.

15 Correa CN, Wu XC, Andrews PA, et al. Cancer incidence and mortality in Louisiana, 1992-1996. New Orleans, LA: Louisiana Tumor Registry, 2000.

16 Gottlieb MS, Shear CL, Seale DB. Lung cancer mortality and residential proximity to industry. Environ Health Perspect 1982;45:157-64.

17 Correa P, Pickle LW, Fontham ETH, et al. The causes of lung cancer in Louisiana. In: Mizell M, Correa P, eds. Lung cancer: causes and prevention. Proceedings of the International Lung Cancer Update Conference, New Orleans, 3-5 March 1983. Deerfield Beach, FL: Verlag Chemie International, 1984:73-82.

18 Marsh GM, Ehland J, Sefcik S. Mortality and population data system (MPDS). Technical Report. Department of Biostatistics, University of Pittsburgh, 1987.

19 National Center for Health Statistics. Leading causes of death. National Vital Statistics Reports 1998;48(11).

20 Keyfitz N. Sampling variance of standardized mortality rates. Hum Biol 1966;38:22-41.

21 Gloeckler LA, Eisner MP, Kosary CL, et al, eds. SEER cancer statistics review, 1973-1997. NIH Publication No. 00-2789. Bethesda, MD: National Cancer Institute, 2000.

22 US Census Bureau. Census of Population and Housing, 1990. http:// www.census.gov/population/www/index.html. Accessed 12 December 2001.

23 National Center for Health Statistics. Vital statistics of the United States, 1975. Vol. II: Mortality. Part A. Hyattsville, MD: US Department of Health, Education, and Welfare, 1979.

24 National Center for Health Statistics. Vital statistics of the United States, 1985. Vol. Il: Mortality. Part A. Hyattsville, MD: US Department of Health and Human Services, 1988.

25 National Center for Health Statistics. 1995 multiple causes of death file, CDROM Series 20, No. 16. Hyattsville, MD: US Department of Health and Human Services, November 1999.

26 US Census Bureau. Population Estimates for States by Race and Hispanic Origin: 1 July 1999. http://eire.census.gov/popest/archives/state/srh/ srhmars.txt. Accessed 10 April 2003.

27 Chiang CL. The life table and its applications. Malabar, FL: Krieger Publishing Company, 1984:137-51.

28 Hearey CD, Ury H, Siegelaub A, et al. Lack of association between cancer incidence and residence near petrochemical industry in the San Francisco Bay area. J Natl Cancer Inst 1980;64:1295-9.

29 Lyons RA, Monaghan SP, Heaven M, et al. Incidence of leukaemia and lymphoma in young people in the vicinity of the petrochemical plant at Baglan Bay, South Wales, 1974 to 1991. Occup Environ Med 1995;52:225-8.
30 Sans S, Elliot I, Shaddick G, et al. Cancer incidence and mortality near the Baglan Bay petrochemical works, South Wales. Occup Environ Med 1995;52:217-24

31 Wilkinson $\mathbf{P}$, Thakar B, Walls $\mathrm{P}$, et al. Lymphohaematopoietic malignancy around all industrial complexes that include major oil refineries in Great Britian. Occup Environ Med 1999;56:577-80.

32 Riggan WB, Van Bruggen J, Acquavella JF, et al, eds. US cancer mortality rates and trends, 1950-1979, Volume I-III. NCI/EPA Interagency Agreement on Environmental Carcinogenesis. Washington, DC: US Government Printing Office, 1983.

33 US Centers for Disease Control and Prevention. Behavioral risk factor surveillance system survey data. Atlanta, GA: Centers for Disease Control and Prevention, 1995.

34 US Department of Health and Human Services, Health Resources and Services Administration. Community health status reports. Rockville, MD: Health Resources and Services Administration, Association of State and Territorial Health Officials, National Association of County and City Health Officials, Public Health Foundation, 2000

35 US Department of Health and Human Services, Health Resources and Services Administration. State profile for Lovisiana. Rockville, MD: Health Resources and Services Administration, 1997.

36 Fontham ETH, Pickle LW, Haenszel W, et al. Dietary vitamins A and C and lung cancer risk in Louisiana. Cancer 1988:62:2267-73.

37 Byers T. Diet as a factor in the etiology and prevention of lung cancer. In: Samet JM, ed. Epidemiology and lung cancer. New York, NY: Marcel Dekker, 1994:335-52.

38 US Centers for Disease Control and Prevention, Nutrition Program. Ten-state nutrition survey, 1968-1970. US Department of Health, Education and Welfare, Publication (HSM), 1972:72-8129 to 8133 .

39 Greenberg RS, Mandel JS, Pastides H, et al. A meta-analysis of cohort studies describing mortality and cancer incidence among chemical workers in the United States and Western Europe. Epidemiology 2001;12:727-40.

40 Louisiana Cancer and Lung Trust Fund Board. Lower Mississippi River Interagency Cancer Study. http://www.Icltfb.org/Cancer/lmrics.htm. Accessed 27 August 2002.

41 Falk R, Pickle L, Fontham ETH, et al. Lifestyle risk factors for pancreatic cancer in Louisiana: a case-control study. Am J Epidemiol 1988;128:324-36.

42 Ekbom A, Hunter D. Pancreatic cancer. In: Adami H-O, Hunter D Trichopoulos D, eds. Textbook of cancer epidemiology. Oxford: Oxford University Press, 2002:233-47.

43 Fontham ETH, Correa P, Chen V, et al. Tobacco and cancer. J La State Med Soc 1988; 140:29-40

44 Correa P, Fontham ETH, Chen V, et al. Diet, nutrition and cancer. J La State Med Soc 1988; 140:43-9.

45 Anderson KE, Potter JD, Mack TM. Pancreatic cancer. In: Schottenfeld D, Fraumeni JF, eds. Cancer epidemiology and prevention. New York, NY: Oxford University Press, 1996:725-71.

46 Institute of Medicine. Improving health in the community. Washington, DC: National Academy Press, 1997:45-50.

47 Lynch J, Kaplan G. Socioeconomic position. In: Berkman LF, Kawachi I, eds. Social epidemiology. New York: Oxford University Press, 2000.

48 Coughlin SS, Calle EE, Patel AV, et al. Predictors of pancreatic cancer mortality among a large cohort of United States adults. Cancer Causes Control 2000;11:915-23.

49 National Center for Health Statistics. Health, United States, 1998 with socioeconomic status and health chartbook. Hyattsville, MD: National Center for Health Statistics, 1998

50 Louisiana Department of Health and Hospitals, Office of Public Health. Parish health profiles 1999. Baton Rouge, LA: Louisiana Department of Health and Hospitals, 1999.

51 Mokdad AH, Ford ES, Bowman BA, et al. Diabetes trends in the U.S.: 19901998. Diabetes Care 2000;23:1278-83.

52 Selvin S. Two issues concerning the analysis of grouped data. Eur J Epidemiol 1987;3:284-7. 